\title{
Gerakan Darul Islam: Catatan Kecil dari Pengalaman Sejarah
}

Ghofar Asnanto

Aktivis sosial dan mahasiswa S-2 Universitas Paramadina

\section{Abstract}

On 7 August 1949 NII was officially proclaimed in the village of Cisampang. As a state based on Islam, Kartoswirjo and his friends formed a constitution which he called Kanun Azazy. His government is called a republic. Its leader is called the Imam (Imamate Council). And form an advisory board or fatwa council whose job is to advise the government. The NII continued to survive, and even expanded its strength in the years after its formation in the late 1950s, even reaching its peak in the late 1957s. When his troops reached 13,129 with firearms around 3000. At that time there was no soldier of the Republic of Indonesia who dared to go into the Darul Islam region which was declared de facto. In Tasikmalaya they control almost $1 / 5$ of the population.

\section{Keywords}

Darul Islam Indonesia; pemberontakan; Kartosumirya, Belanda

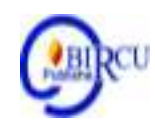

\section{Pendahuluan}

Darul Islam (dar al-islam) yang seringkali dipertentangkan dengan dar al-harb (daerah yang harus diperangi, daerah kafir) adalah kelompok yang coba mendirikan negara Islam di Indoesia. Bemula dari saat Jepang kalah pada perang dunia II dan salah satu implikasinya, mereka kemudian mundur dari daerah jajahannya. Pada saat itu, belum terbentuk Pemerintah Republik Indonesia. Namun dengan adanya kalangan muda nasionalis berpendidikan tinggi yang tak mengindetifikasi dirinya pada masyarakat lokal, tetapi pada masyarakat yang lebih luas: Indonesia, berhasillah Pemerintah Republik terbentuk setelah proklamasi 17 agustus 1945 setelah melalui sidang-sidang persiapan kemerdekaan yang dilakukan sebelum proklamasi.

Pemerintahan rebublik terbentuk. Di daerah-daerah kawasan Indonesia dipimpin oleh pemimpin-pemimpin tradisional. Namun, karena cepatnya proses proklamasi ini, Indonesia belum mempunyai tentara resmi yang mengamankan daerah-daerah itu. Meskipun ada yang namanya Badan Keamanan Rakyat (BKR), namun sebagian besar dari mereka masih berasal dari Jepang yang tentu disamarkan, hingga pada akhirnya menjadi Tentara Kemanan Rakyat (TKR).

Pemimpin-pemimpin tradisional yang diangkat oleh pemerintah pusat pada waktu itu, dalam rekam jejaknya melakukan hal-hal yang sangat merugikan rakyat, berkolaborasi dengan pihak imperealis, dan akibatnya rakyat semakin sengasara. Sehingga dengan kebijakan inilah, seringkali terjadi perlawanan atau pemberontakan terhadap pemerintah daerah tradisional tersebut. Juga seringkali karena akibat ketidakpuasan dari masyarakat lokal atas kepemimpinan pemimpin tradisional. Perlawanan itu umumnya dipimpin oleh pemimpin atau pemuka Islam. Sehingga pada tahap kemudian terjadilah pemberontakan yang terkenal dengan Pemberontakan Darul Islam atau Tentara Islam (DI/TII).

Pembentukan kelompok ini memang terbilang mudah, karena pemimpin muslim dengan mudahnya memobilisasi masyarakat setempat. Terlebih mereka juga terlibat saat-saat turut 
serta bersama-sama melawan para penjajah: Belanda dan Jepang. Juga tidak adanya kontak dengan pemerintah pusat. Sehingga setelah mereka-Belanda dan Jepang-keluar, kelompok ini gampang terbentuk dengan mobilisasi rakyat melalui prinsip-prinsip ajaran Islam. Pemberontakan ini bisa dilihat di Jawa Barat, Aceh, Jawa Tengah, dll. Jadi peranan pemimpin Islam sedari awal memang sudah terlihat. Tak heran kalau kemudian mereka menginisiasi terbentuknya kelompok pemberontak itu.

Walaupun membentuknya cukup mudah, namun terbilang agak lambat. Apa alasannya? Karena sejak awal belum dipersiapkan suatu pemikiran tentang konsep negara Islam, terutama saat-saat Indonesia masih diduduki Jepang. Hampir semikiran pada saat itu terusat pada terpusat pada satu misi yaitu untuk mengusir penjajah dari tanah pribumi. Karena itu kristalisasinya melambat. Baru setelah ada pemerintah Republik yang banyak melahirkan kekecewaan pada pihak mereka (kalangan masyarakat muslim), maka gagasan Negara Islam Indonesia yang dimotori oleh DI terbentuk.

Yang juga perlu diperhatikan adalah, bahwa yang juga menjadi mula dari terbtuknya gerakan DI ini, sebagai akibat dari politik kebijaksanaan Jepang yang memberi keleluasaan terhadap pemimpin-pemimpin Islam untuk memobilisasi rakyat-sehingga leluasa berpolitik-untuk mengadakan kegiatan keagamaan (indoktrinasi) dan kegiatan sosial. Sementara sebelumnya, pada saat Belanda berkuasa, kegiatan politik kaum agamawan tidak diperbolehkan. Kebijakan Jepang ini bisa dipahami sebagai alasan politik untuk memecah belah bangsa Indonesia. Gerakan Islam semakin tumbuh dan pengikutnya banyak dan patut diperhitungkan. Maka di saat yang sama, Jepang juga menebarkan propagandanya agar para pemimpin Islam leluasa menarik anggotanya ke kelomponya. Sehingga tak jarang terjadi benturan dengan pemrintah daerah. Dan pada akhirnya terpecahlah kelompk-kelompok lokal ini. Tak jarang, juga terjadi benturan dengan pemimpin tradisionalis di daerahnya masingmasing. Inilah perwujudan politik jepang paling nyata.

Tetapi lama-kelamaan masyarakat muslim kecewa, lantaran apa yang mereka kerjasamakan dengan Jepang tidak sesuai dengan apa yang selayaknya mereka terima. Sehingga gejolak untuk melakukan revolusi sosial seringkali terjadi. Pada saat Indonesia merdeka, maka dibentuklah tentara Republik Indonesia yang terorganisir dengan cukup baik, lalu dikirim ke daerah-daerah yang terjadi pemberontakan terhadap pemimpin tradisional. Segera revolusi-revolusi sosial itu menghilang. Dan kalau pemberontakan cukup dahsyat, seringkali aktor-aktornya yang kemudian mendeklarasikan dirinya sebagai pemimpin ditangkap, dan digeser dengan pemimpin baru.

Revolusi-revolusi sosial itu terjadi pada tahun pertama perjuangan kemeredekaan. Kecuali di Aceh. Ledakan revolusi terjadi akibat ketidakpuasan pada saat penjajah menghisap mereka. Mereka memang sering memasukkan komponen Islam, tapi bukan gerakan dengan kerangka nasional, melainkan sekalanya lokal.

\section{Kajian Pustaka}

\section{Polemik Deklarator dan Proklamator DI /TII}

Gerakan ini bermula di Jawa Barat (Tasikmalaya-Ciamis) yang dikepalai oleh seorang ulama bagian tenggara Jawa Barat. Sesaat sebelum proklamasi, mereka bersiap-siap melakukan demonstrasi. Pada saat itu konon mereka seharusnya memproklamasikan Negara Islam Indonesia, sebagaimana dikatakan oleh CAO van Nieuwenhuijze. Namun proklamsi itu dihentikan oleh tokoh setempat yang takut akan kesulitan dari pihak Jepang. Walaupun tak ada proklamasi, namun Inilah yang menandai awal mula Darul Islam. Gerakan yang mulamula berada di tangan kiai pemimpin kerohanian ini, yaitu kiai Yusuf Tauziri (sebagaimana diidentifikasi oleh Hiroko Horikoshi), lambat laun diterima oleh seorang politikus muslim 
bernama S. M. Kartoswirjo. Mungkin Yusuf Tauziri punya pengaruh, namun tak seberapa. Ia yang menandai gejala saja, ketimbang pada tahap selanjutnya ketika muncul gerakan pembrontakan bersenjata Darul Islam. Tak lebih.

Kartoswirjo pada tahun 1949 memberontak terhadap Republik, dan Yusuf tauziri menarik dukungannya dari Kartiswirjo. Lalu menjadi pemimpin Darul Islam (Dunia Perdamaian): gerakan untuk mendirikan Negara Islam dengan cara damai. Sebelumnya setelah Jepang menyerah pada perang dunia kedua, 15 Agustus, Kartoswirjo konon meminta Yusuf Tauziri untuk mendeklarasikan NII, tapi kiai itu menolak.

Dalam versi lain, Kartoswirjo lah yang dianggap pemimpin Darul Islam pertama kali. Sebab, konon dialah yang mula-mula memproklamasikan Darul Islam (NII) sejak 14 agustus 1945 yaitu hari-hari sekitar Jepang menyerah (15 Agustus). Namun proklamasinya ditarik kembali setelah Soekarno memproklamasikan Republik Indonesia pada 17 Agustus 1945. Namun hal ini lemah. Karena tidak mungkin Jepang mengizinkannya. Kalaupun memang terjadi, hal itu tentu akan diketahui oleh khalayak umum. Namun hal itu tidak ada. Kecuali kemungkinan di daerah-daerah kecil dengan lingkaran pertemuan yang kecil dan bersifat rahasia. Atau barangkali di daerah Banten, karena di sanalah ia menjadi pengawas latihan gerilya yang diprakarsai Jepang di sekitar Malangbong. Ini juga tidak mungkin, karena kabarkabar akan menyerahnya Jepang pada saat itu hanya terbatas di Jakarta saja dan tidak sampai ke Banten maupun Tasikmalaya.

Selain Darul Islam yang dijalankan dengan cara Damai oleh Yusuf Tauziri, ada juga bentuk kedua, yaitu oposisi dengan senjata terhadap Republik. Hal itu muncul di tahun-tahun kemudian.

Bagaimana Dl menjadi gerakan nasional? Awalnya muncul kesadaran di kalangan DI bahwa agar Darul Islam terbentuk secara konkret dan menasional, maka diperlukan pemimpin yang tak lagi terikat dengan perasaan lokal atau yang tak lagi mengidentifikasi dirinya dengan lokalitas dimana ia berada. Tetapi yang lebih mementingkan masyarakat muslim secara luas: Indonesia. Maka tampillah Kartoswirjo ke permukaan menghilangkan batas-batas lokalitas itu. Ia berpengalaman dalam politik nasional, tetapi juga cukup mesra terhadap masyarakat lokal untuk menarik mereka dalam satu gerakan.

Pada awalnya - sebagaimana disebut di muka tulisan ini-perbedaan ideologi tak diperhitungkan, malah dikesampingkan, guna bersatu melawan penjajah (Belanda dan Jepang). Walaupun pada saat itu terbentuk Tentara Islam Indonesia (TII) pada tahun 1948, hal itu tak menimbulkan pertempuran terbuka, sekalipun hal itu bisa memicu perpecahan akibat persiapan pembentukan Neraga Islam. Maka Pada tahun 1948 DI konkret terbentuk.

Apa yang memicu pemberontakan Darul Islam terhadap Republik? Salah satu yang paling mencolok adalah karena adanya persetujuan terhadap perjanjian Renvile (antara Repuplik dan pemerintah Belanda yang coba menguasai lagi Jawa Barat untuk mendirikan Negara Pasundan) pada januari 1948. Salah stu kebijakannya adalah bahwa pasukan Republik akan ditarik dari daerah-daerah yang dikuasi oleh Belanda seperti di Jawa Barat sebelah Barat, Jakarta dan bagian-bagian Jawa Tengah dan Jawa Timur. Persetujuan ini melahirkan opisisi yang hebat terhadap Republik, dan memuncak pada krisis kabinet. Dan ketika itu perdana menteri Amir Sjafrifuddin berhenti.

Sebenarnya banyak tentara yang menentang, tetapi karena harus menaati apa isi perjanjian itu, akhirnya mereka mundur ke daerah-daerah yang dinyatakan sebegai daerah Republik sebagaimana dinyatakan dalam perundingan Renvile. Pada 2 Februari devisi Siliwagi Republk "hijrah"-kata yang digunakan untuk menyatakan bahwa hal itu hanya sementara, dan pada akhirnya akan kembali dan menguasai secara keseluruhan - ke Jawa Tengah dari Jawa Barat. Hal ini banyak melahirkan pertantangan-pertentangan dari pihak gerilya di luar tentara Republik. Mereka menentang dengan keras isi perundingan itu. Karena 
itu, sekalipun banyak tentara Republik meningggalkan daerah yang dinyatakan dikuasi belanda, tetapi banyak gerilya-gerilya yang tetap tinggal menentang isi Renvile itu.

Siapa saja yang menolak pindah dari daerah yang dinyatakan dikuasi Belanda? Beberapa diantaranya adalah kesatuan dua pasukan Hizbullah dan Sabilillah. Dua organisasi cabang bersenjata dari partai Islam, Masyumi. Kebijakan politisi partai Masyumi untuk turut pindah dari Jawa Barat akibat perjanjian Renvile itu ditentang oleh Hizbullah dan Sabilillah yang akan tetap tinggal di Jawa Barat, sekalipun partai ini manarik dukungan dari kabinet Amir Sjarifuddin karena persetujuan Renvile. Tetapi para politisi itu tetap menganggap bahwa diri mereka tetap terikat dengan pedundingan itu. Karena bagi politisi Masyumi, hal itu ditandatangani oleh pemerintah Republik yang sah.

Di samping Hizbullah dan Sabililah, ada politisi Masyumi yang juga menentang kebijakan partai, yaitu Kartoswirjo. Alasannya adalah karena perjuangan melawan Belanda harus dilanjutkan dan tak ada alternatif lain kecuali menetap di Jawa Barat. Ia memimpin dan mengkordinasi perlawanan itu. Dia mengorganisir Hizbullan dan Sabilillah serta gerilya sipil melalui pembinaan administrasi militer. Keduanya dibentuk sebagai Tentara Islam Indonesia, dan membentuk struktur pemerintahan dasar.

Setahun kemudian, Devisi Siliwangi Republik kembali ke Jawa Barat. Namun tentu yang dihadapi adalah mereka masyarakat yang dikecewakan oleh Republik. Karena mereka merasa bahwa mereka lah yang berjasa dalam melawan Belanda. Republik berusaha merebut kembali Jawa Barat, dan hal itu mendapatkan perlawanan yag sengit dari masyarakat (perang). 15 tahun lamanya. Barulah pemberontakan itu dapat ditumpas setelah Kartoswirjo ditangkap pada 1962. Satu tahun di di Jawa Barat kelompok gerilya itu dibiarkan bertindak sesuak hati. Ternyata sangat menentukan bagi pengusiran Belanda dari tanah Jawa Barat.

\section{Pembahasan}

\subsection{Sekarmadji Maridjan Kartoswirjo}

Organisator ulung. Mempunyai komiten untuk menumpas imprealisme. Menyukai pedesaan dari pada perkotaan (Jakarta). Suka terhadap masyarakat desa. Sebelum perang ia dengan tegas menentang perjanjian Renvile. Orangnya non-kompromistis. Sehingga hal itulah yang menjadikan karir politiknya cemerlang, sesaat seblum perang. Dia begitu menonjol pada saat Jepang, sementara pada saat awal-awal revolusi Indonesia, ia sangat mengecam politik yang dianut oleh partai-partai politik dan repulik Indonesia. Sehingga dengan menjauh dari kehidupan politik perkotaan, ia tak perlu dilema untuk terus perang mati-matian melawan Balanda.

Lahir di Capu 7 februari 1905, perbatasan Jawa Tengah dan Jawa Timur. Ayahnya seorang mantri penjual candu. Terbilang mampu secara ekonomi. Kartoswirjo sekolah di pendidikan pribumi yang terbaik yang hanya menerima anak-anak pribumi yang mampu dan anak ningrat. Agak mengherankan, karena secara pendidikan, ia dididik di pendidikan sekuler, tetapi lama-kelamaan menjadi pemimpin pemberontakan pasukan Islam.

Sekolah yang dimasukinya antara lain Sekolah Bumiputera Kelas Dua yang di dalamnya diajari pelajaran bahasa Belanda. Pengetahuan bahasa Belanda pada waktu itu menjadi prasyarat untuk melanjutkan pada pendidikan selanjutnya, dan untuk kebutuhan diterima dalam pekerjaan administratif. Lalu melanjutkan ke Sekolah Dasar Satu, laluSekolah Dasar Eropa. Sekolah itu adalah sekolah elit bagi kalangan pribumi. Karena sekolah bumiputera bahasa Belanda (HIS) adalah sekolah yang dimaksudkan untuk pribumi kelas atas. Sekolah dasar Eropa itu pada mulanya dimaksudkan untuk kalangan Eropa dan IndoEropa, namun juga secara terbatas pribumi diperkenankan masuk. Karena pertama, dari situ diharapkan dapat melanjutkan pendidikan menengah dan tinggi setelah dilihat latar belakang 
sosialnya. Kedua, anak-anak dengan bakat khusus akan melanjutkkan pada lembaga yang mendidik dokter bumiputera dan ahli hukum atau pegawai negari. Kartoswirjo pada kategori yang kedua. Kemudian ke Surabya, masuk sekolah dokter Hindia Belanda (NIAS). Pada tahun 1927 ia harus keluar, karena-seperti anak muda pada masanya-terlibat dalam hal politik yang memaksanya dikeluarkan dari NIAS atau sekolah kedokterannya. Ia masih berumur 18 tahun. Karena memang pada masa itu Surabaya menjadi tempat gerakan politik nasionalis.

Kepiawaiannya dalam memainkan peta poitik ia terima dari mentornya-sama seperti Soekarno-yaitu HOS. Cokroaminoto. Keduanya tinggal di rumah yang sama selama kurun waktu yang hampir sama lamanya. Hanya saja kalau Soekarno seringkali berselisih pendapat dengan Cokro (terutama setalah kawin dengan putrinya dan menceraikannya), sementara Kartoswirjo tetap setia pada politik Sarekat Islam. Ia tinggal bersama Cokro setelah dikeluarkan dari NIAS. Ia menjadi semacam sekretaris Cokro sampai 1929. Cokro adalah seorang yang sangat keras menantang Belanda dan selalu menyarankan perlawanan terhadapnya. Rumahnya menjadi pusat anti-kolonial di Surabaya. Rumahnya menjadi tempat pertemuan orang-orang yang aktif berpolitik pada masa remajanya. Tetapi pada 1927, ketika kartoswirjo mondok di rumahnya, Cokro dalam gerakan nasionalis sudah mulai berubah. Dia mendapat banyak kecaman, dan Sarekat Islam-nya yang mempersatukan Islam, nasionalis, dan komunis, merosot mejadi Islam kecil. Orang-orang komunis di SI mengarahkannya ke arah yang lebih radikal. Dan puncaknya Cokro dipecat dari SI. Lalu muncul gerakan nasionalis-sekuler pimpinan Soekarno yang mengambil alih pengaruh SI. Selain kemerosotan SI yang diakibatkan di atas, juga karena kalah bersaing dengan oraganisasi baru Muhammadiyah dan NU.

Persamaannya denga Soekarno adalah Kartoswirjo juga terlibat dalam organisasi Jong Java (Pemuda Jawa) sekalipun masanya beda dan sama-sama menarik dari organisasi ini. Lalu Jong Java pecah. Pemuda-pemuda meninggalkan organisai itu untuk membentuk Jong Islamiten Bond (Liga pemuda muslim). Dan Kartoswirjo masuk organisasi yang didirikan oleh H. Agus Salim ini beberapa bulan setelah berdirinya. Ia menjadi salah satu pemimpinnya. Pada titik inilah ia dikeluarkan dari NIAS. Dengan tuduhan melakukan aktivitas politik dengan bacaan cenderug komunis - maksudnya tak lebih dari mengecam pemerintah kolonial.

Lalu hubungannya dengan Cokro semakin mesra, terutama ketika ia masuk ke SI, yang pada saat itu telah berubah menjadi Partai Sarekat Islam (PSI): tujuannya bercita-cita dan berpandangan Islam internasional. Tekanan politinya semakin kuat ketika dibumbuhi "partai". Lalu partai ini berubah lagi menjadi PPSI pada tahun 1930 yang tentu perjuangan Indonesia sendiri lebih didahulukan dari pada pandangan internasional Islam sendiri.

Perlu dilihat bahwa PSI dan Jong Ismamiten Bond adalah organisasi muslim modernis. Salah satu cirinya adalah kembali ke Al-Quran dan Sunnah, menentang bidah dan tahayul, khurafat. Hal itu tentu berlawanan dengan muslim tradisionalis. Lalu apakah Kartoswirjo serasi dengan hal itu? Ternyata tidak cocok. Dia yang sangat minim pengetahuan Islamnya, dan kemapunan bahasa Arab yang tidak mumpuni, bahkan ia belajar Islam dari Quran terjamahan saja. Pendiikan Islam-nya itu didapat di kemudian hari. Sehingga dengan keterbatasan bahasa itulah, menyebabkan ia sulit berinteraksi dengan buku-buku berbahasa Arab karya pemikir muslim. Pengetahuan Islam yang lebih sempurna didapat dari perjumpaan tidak sengaja dengan ulama-ulama Islam.

Lalu kemudian ia pindah ke Malangbong, kota kecil dekat Garut dan Tasikmalaya. Di situlah ia menimba ilmu agama pada Yusuf Tauziri dan kepada mertuanya, Ardiwisastra. Mertuanya adalah anggota PSII terkemuka, seorang guru agama yang masyhur di daerahnya. Sementara di Malangbong moderisme Islam belum menyentuhnya secara mendalam. Malah 
hal itu hanya menjadi gejala perkotaan saja. Tidak di pedesaan. Akibanya pendidikan Islam yang diterima Kartoswirjo hanya sedikit bercirikan modernisme. Terlebih kecenderungannya pasa sufisme. Ia menjadi sufi. Yang beberapa ciri khusunya adalah mistik, pemujaaan, kultus, dll. Sehingga hal itu tentu menjadi antitesis dari modernism PSSI. Sehingga hal itu pulalah yang mengakibatkan perpecahan dengan pimpinan PSII. Tetapi tetap mendapat dukungan msyarakat setempat. Hal inilah yang juga mendorong pemberontakan yang didukung oleh masyakrat desa, selain memang kepiawaiannya memanfaatkan kepercayaan masyarakat desa. Selain itu, ia juga digadang-gadang sebagai Ratu Adil. Sehingga komplitlah kepercayaan rakyat desa padanya.

Singkat cerita Kartoswirjo dikeluarkan dari partai politik PSII bersama rekan lainnya Yusuf Tauziri dan Kamran. Dipicu oleh gejolak politik yang terjadi di dalamnya. Tetapi mereka menolak pemecatan dan membentuk KPK-PSII (Komite Pertahanan Kebenaran PSII). Namun menyadari hal ini tak mungkin dilakukan, maka dibentuklah partai yang bebas. Namun maksud yang terselubung adalah bahwa komite akan berkembang menjadi PSII yang sebenarnya. Karena PSII sebelumnya yang memecat dirinya dan kawan-kawan dirasa telah menghianati rakyat Islam yang berjuang. Oleh karena itu tak layak lagi menggunakan PSII pihak Abiskusno Tjokrosujoso. Lalu Kartiswirjo menjadi pemimpin atau ketua PSII bentukan dirinya. Kadang-kadang kadang disebut dengan PSII kedua: yang mengaggap bahwa politik PSII lama harus dilanjutkan dan bahwa politikhijrah harus tetap diteruskan. Bahkan harus dilanjutkan dengan cara lebih radikal. Lalu PSII bayangan Kartoswiryo ini lama-lama banyak mempunyai cabang, bahkan ada sekitar 21 cabang seprti dikatakan oleh Prianggdigodo (1950). Tetapi pendapat lain mengatakan bahwa KPK-PSII hanya berhasil di Jawa Barat dan hanya punya 6 cabang bekas PSII yang hadir (Hrikoshi, 1975). Nah anggota PSII kedua inilah yang menjadi titik mula perekrutan kader Darul Islam. Lalu PSII kedua ini melalui kongres Maret tahun 1940 mengesahkan pendirian institute suffah di Malangbong. Pada mulanya dimaksudkan untuk meberikan pendidikan umum dan agama, tetapi lama-kelamaan menjadi tempat pelatihan militer selama pendudukan Jepang. Lambaga ini disusun dengan sistem madrasah atau pesantren Islam. Di dalamnya Kartoswiryo mengajarkan ilmu tauhid yang dogmatik. Juga diajarkan bahasa Belanda dan astrologi. Dan siswa yang mendapat didikan militer di Institute Suffah pada akhirnya bergabung dengan gerilya Hizbullan da Sabilillah yang nantinya menjadi inti dari Tentara Islam Indonesia (TII) yang kemudian menjadi pasukan pemberontakan Darul Islam.

Meletusnya pemberontakan Darul Islam salah satu sebab lainnya dalah barangkali persoalan konstitusi dan dasar negara. Pada mulanya usulan memasukkan Piagam Jakarta yang memasukkan butir-butir "dengan kewajiban melaksanakan syariat Islam bagi pemeluknya" agar dimasukkan dalam mukaddimah konstitusi sempat menjadi perdebatan panjang pada rapat Panitia Persiapan Kemerdekaan Indonesia (PPKI), dan pada rapat terakhir persiapan kemerdekaan ternyata memang Piagam Jakarta dimasukkan, tetapi syarat kewajiban menjalankan syariat Islam bagi pemeluknya tidak dimasukkan ke dalamnya. Artinya kembali pada mukaddimah sebelum piagam Jakarta, dan hanya memasukkan "Ketuhanan Yang Maha Esa" dan seterusnya. Dan juga perubahan lain adalah bahwa bunyi konstitusi yang menyatakan bahwa presiden harus berasal dari orang Islam juga dihilangkan. Pada perkembangan selanjutnya ternyata Indonesia menjadi negara sekuler. Itulah yang ditengarai menjadi pemicu meletusnya pemberontakan Darul Islam. Selain itu memang Kartoswirjo tidak punya akses untuk menyuarakan pendapatnya di hadapan panitia persiapan kemeredekaan. 


\subsection{Proklamasi NII (Darul Islam)}

Untuk memproklamasikan NII (DI), Kartoswirjo masih bersabar. Hal itu bukan tidak mungkin dilakukan. Tetapi karena Soekarno dan Hatta telah lebih dulu memproklamirkan kemerdekaan Indonesia. Maka urunglah untuk juga memproklamasikan NII. Konon sebelumnya sepat meminta Yusuf Tauziri untuk memproklamirkan NII pada tahun 1948. Salah satu faktornya barangkali ada kaitannya dengan perjanjian Renvile. Namun kiai itu menolak. Kartoswirjo menahan diri untuk tidak memproklamirkan NII selama setahun. Selama itu ia merasa semakin menjadi raja di Jawa Barat. Ia menganggap menjadi pemimpin gerilya anti Belanda di sana. Pada 7 Agustus 1949 NII secara resmi diproklamasikan di desa Cisampang. Sebagai sebuah negara yang berasaskan Islam, Kartoswirjo dan kawan-kawan membentuk konstitusi yang ia sebut dengan Kanun Azazy. Pemerintahannya disebut dengan republik. Pemimpinnya disebut dengan Imam (Dewan Imamah). Dan membentuk dewan penasihat atau dewan fatwa yang bertugas memberi nasehat pada pemerintahan.

NII terus bertahan, dan bahkan meluaskan kekuatannya pada beberapa tahun setelah pembentukannya pada akhir-akhir 1950-an, bahkan mencapai puncak kekuatannya pada akhir-akhir 1957-an. Pasukannya ketika itu mencapai 13.129 dengan senjata api sekitar 3000an. Pada waktu itu tak ada seorang prajurit Republik Indonesia yang berani massuk ke wilayah Darul Islam yang dinyatakan secara de facto. Di Tasikmalaya mereka hampir menguasai 1/5 dari penduduknya. Dan mereka melakukan serangan melalui tembakan, baik dari dalam maupun di luar kota baik di Tasikmalaya sendiri maupun di Garut. Dari laporan tiap tiga bulannya, korban yang terbunuh arena serangan itu berjumlah ratusan orang, ribuan rumah terbakar, ada juga korban perampokan yang jumlahnya ribuan juga. Brutal.

Apa motif penyerangan itu? Suatu desa diserang karena dicurigai terlibat konspirasi dengan tentara Republik. Atau dengan alasan lain, yaitu merampok penduduk desa dengan legitimasi harta rampasan perang atau ghanimah sebagaimana dahulu terjadi di dunia Islam sejak zaman nabi. Maka pada saat itulah NII atau DI menjadi ancaman ang sangat berat bagi Republik. Selain itu pendudk desa yang ditengarai berkonspirasi dengan tentara republik, mereka diculik dan dipaksa masuk NII.

Namun yang demikian bukan berarti tentara Republik tidak cukup suksesdalam menumpas NII, mereka juga mengejar-ngejar pasukan NII dan menangkap pemimpinpemimpinnya, bahkan dibunuh. Yang menyebabkan tentara Republik juga berhasil melakukan penangkapan ini karena ada faktor internal yang menyebabkan DI terpecah. Hal itu dari faktor perebutan kekuasaan di kalangan ulul amri: perebutan kekuasaan imam dan wakil imam (naibul imam). Atau juga adanya ketidakpuasan pembagian harta rampasan perang yang mereka sebut dengan ghanimah. Tentara Republik mencapai puncak kesuksesannya ketika merek berhasil menangkap dan membunuh pemimpin NII ada waktu yang bersamaan yaitu pada juli 1951. Itulah kesuksesan terbesar tentara RI.

\section{Kesimpulan}

Bagaimana teknik yang dilakukan tentara Republik dalam menumpas pasukan NII? Memutus perbekalan mereka agar kelaparan dan berangsur-angsur menyerah. Satu hal lain yang juga dilakukan adalah dengan menduduki sawah yang menjadi sumber pembekalan mereka. Sehingga koneksi makanan yang mereka harusnya dapatkan lumpuh. Biasanya sawah ini dikerjakan oleh para kerabat pasukan NII. Kartoswirjo coba membalas apa yang dilakukan pasukan Republik dengan menyeru kepda "perintah perang semseta" pada awal 1961. Sebagian mereka berpakaian seperti prajurit. Sehingga susah dikenal. Dan akibatnya banyak dari pasukan republik yang diculik. Namun, prajurit republik tak kehabisan akal. Pada 1962, mereka melakukan "Operasi Barata Yudha": pagar betis. Brawijaya dan diponegoro 
turut ambil bagian. Hingga puncaknya Katoswirjo tertangkap beserta istrinya di sebuah tempat persembunyiannya, di dekat gunung Geber, dekat Cipaku, Cicalengka Selatan. Ketika tertangkap, Kartoswirjo terluka akibat tembakan di paha kanannya. Dan Kartoswirjo sendiri dijatuhi hukuman mati setelah disidang selama tiga hari pada 16 agustus 1962. Maka dengan ini, berakhirlah gerakan NII terorganisir di jawa barat setalah berlangsung kurang lebih 10 tahun.

\section{Daftar Pustaka}

Chaidar, Al. Pemikiran Politik Proklamator Negara Islam Indonesia S. M. Kartosoewirjo, Jakarta: Darul Falah, 1999.

Dengel, Holk H, Darul Islam dan S. M. Kartosoewirjo, Jakarta: Pustaka Sinar Harapan, 1995.

Dijk, Van. C, Darul Islam, Sebuah Pemberontakan, Jakarta : Pustaka Utama Grafiti, 1993.

Mohammad Iskandar, Sekarmadji Maridjan Kartosoewirjo di Penghujung Perjalanan, pengantar dalam Fadli Zon, h. 24

Pinardi, Sekarmadji Maridjan Kartosoewiryo, Jakarta: PT. Aryaguna, 1964. 